\title{
Atmospheric boundary layer simulation in a short wind tunnel
}

\author{
S. M. N. Shojaee $\cdot$ O. Uzol $\cdot$ Ö. Kurç
}

Received: 11 September 2011/Revised: 21 November 2012/Accepted: 27 April 2013/Published online: 28 November 2013

(C) Islamic Azad University (IAU) 2013

\begin{abstract}
This paper presents the design, computational analysis and experimental study of passive device configurations which utilized in the Ankara Wind Tunnel to simulate the atmospheric boundary layer within the test section. The study here is part of a joint project between the Aerospace and Civil Engineering Departments at Middle East Technical University, which involves testing of highrise building models in the Ankara Wind Tunnel. The design consists of spires and rows of cubical surface roughness elements at the inlet. The preliminary computational analysis shows that the current design may provide the desired boundary layer thickness at about $4.0 \mathrm{~m}$ downstream of the test section inlet, which leaves enough room for the building models to be placed in the test section. This study also helps obtaining a preliminary understanding of the boundary layer development and reducing the tunnel operation time and cost during the actual experimentation phase. At the end, experimental results show acceptable results of this study.
\end{abstract}

Keywords Passive device $\cdot$ Spires $\cdot$ Exposure $\cdot$ Modeling $\cdot$ Short wind tunnel

S. M. N. Shojaee ( ()

Department of Aerospace Engineering, Faculty of Mechanical and Aerospace Engineering, Science and Research Branch, Islamic Azad University, Tehran, Iran

e-mail: nimashojaee@ srbiau.ac.ir

O. Uzol

Department of Aerospace Engineering, Middle East Technical University (METU), Ankara, Turkey

Ö. Kurç

Department of Civil Engineering, Middle East Technical University (METU), Ankara, Turkey

\section{Introduction}

Wind tunnel testing is still the primary source of information in wind engineering applications. New facilities and new techniques are continuously being developed for the investigation of a variety of environmental and architectural aerodynamics-related issues (Abbaspour and Shojaee 2009; Bienkiewicz 1996; Cermak 1995). Determining the effects of wind on high-rise buildings, bridges and other architectural structures is of critical importance and is an integral part of the structural design process (American Society of Civil Engineers [ASCE] 2005). Also, wind profile simulation is very important in environmental pollution transportation modeling (Nagheeby and Kolahdoozan 2010; Abdullah et al. 2007; Freddy Kho et al. 2007).

These wind tunnel tests are generally conducted in specialized tunnels known as "boundary layer wind tunnels (BLWT)" in the literature (Cermak 1982; Peishi et al. 2011), which usually have relatively long test sections $(15-20 \mathrm{~m})$ and are specifically designed to create a thick boundary layer velocity profile as well as appropriate turbulence levels to be able to simulate the atmospheric boundary layer (ABL) within the test section. When a BLWT is not available, wind tunnel tests may also be conducted in aeronautical tunnels, which have much shorter test sections in general compared to BLWTs. However, this requires a significant effort in terms of designing appropriate devices to be added at the entrance of the test section in order to create the desired boundary layer properties for the ABL simulation. These passive devices come in many shapes and forms but the most frequently used ones are grids, barriers, fences, spires and cubical roughness elements that are generally placed on the test section floor upstream of the test subject (Simiu and Scanlan 1986). During the past 70 years, many researchers 
have worked on ABL modeling using passive devices (e.g., Ohya 2001; Counihan 1969, 1973; Cook 1973; Cermak 1982, 1995; Cermak et al. 1995; Garg et al. 1997). Other types of passive devices are also introduced by (Cermak 1982) and (Irwin 1981).

To test high-rise building in a short aeronautical wind tunnel, the wind profile and ABL thickness should be created in test section of wind tunnel. So what should be created is the exact model of wind profile, its development through test section length, length downwind of passive devices and desired boundary layer thickness.

The study presented here is part of a joint project between the Aerospace and Civil Engineering Departments at METU, which involves examining wind effects on highrise buildings by testing small-scale models at Ankara Wind Tunnel (AWT) (Fig. 1). AWT is a closed-loop aeronautical wind tunnel with a 3-m wide, 2.44-m high and 6-m-long test section and is driven by a $750 \mathrm{~kW}$ electric motor and an axial fan, which can create test section wind speeds up to $90 \mathrm{~m} / \mathrm{s}$ (SAGE 1998). AWT is the only wind tunnel facility in Turkey that can be utilized for building tests but unfortunately relatively shorter length of its test section compared to BLWTs is an issue (Cermak 2003). In order to utilize the wind tunnel test results during the design of high-rise buildings, ABL as defined in building codes (American Society of Civil Engineers [ASCE] 2005) must be created at the tunnel environment accurately. Because of this reason, investigating every possible option to successfully develop required wind conditions at the test section has crucial importance for future wind tunnel applications in Turkey in the structural engineering area.
Thus, this paper presents the design, computational analysis and experimental study of passive device configurations to be applied in the AWT to simulate ABL within the test section.

The background on ABL simulations in wind tunnels and the design methodology for the passive device configurations are presented in the next section. The computational analysis is performed using the commercial CFD software Fluent.

\section{Materials and methods}

\section{Similarity considerations}

Main requirement for the physical modeling of wind engineering-related phenomena is the proper simulation of natural wind characteristics. Most of the time in the absence of thermal winds, the ABL can extend up to a height of about $200 \mathrm{~m}$ over flat terrain and up to $1,000 \mathrm{~m}$ over large cities. For wind engineering applications, the gradient wind is generally taken to be the maximum mean wind speed of the profile and defines the height of the ABL.

Basic criteria for kinematic, dynamic and thermal similarity can be obtained from the conservation equations of mass, momentum and energy. Geometric similarity can be retained by uniformly scaling horizontal and vertical length scales. As described in (Cermak 1995), in order to achieve "exact" similarity between the model and the prototype, the significant global dimensionless parameters are as follows:

Reynolds number : $R e=U_{0} L_{0} / v_{0}$

Fig. 1 Ankara Wind Tunnel

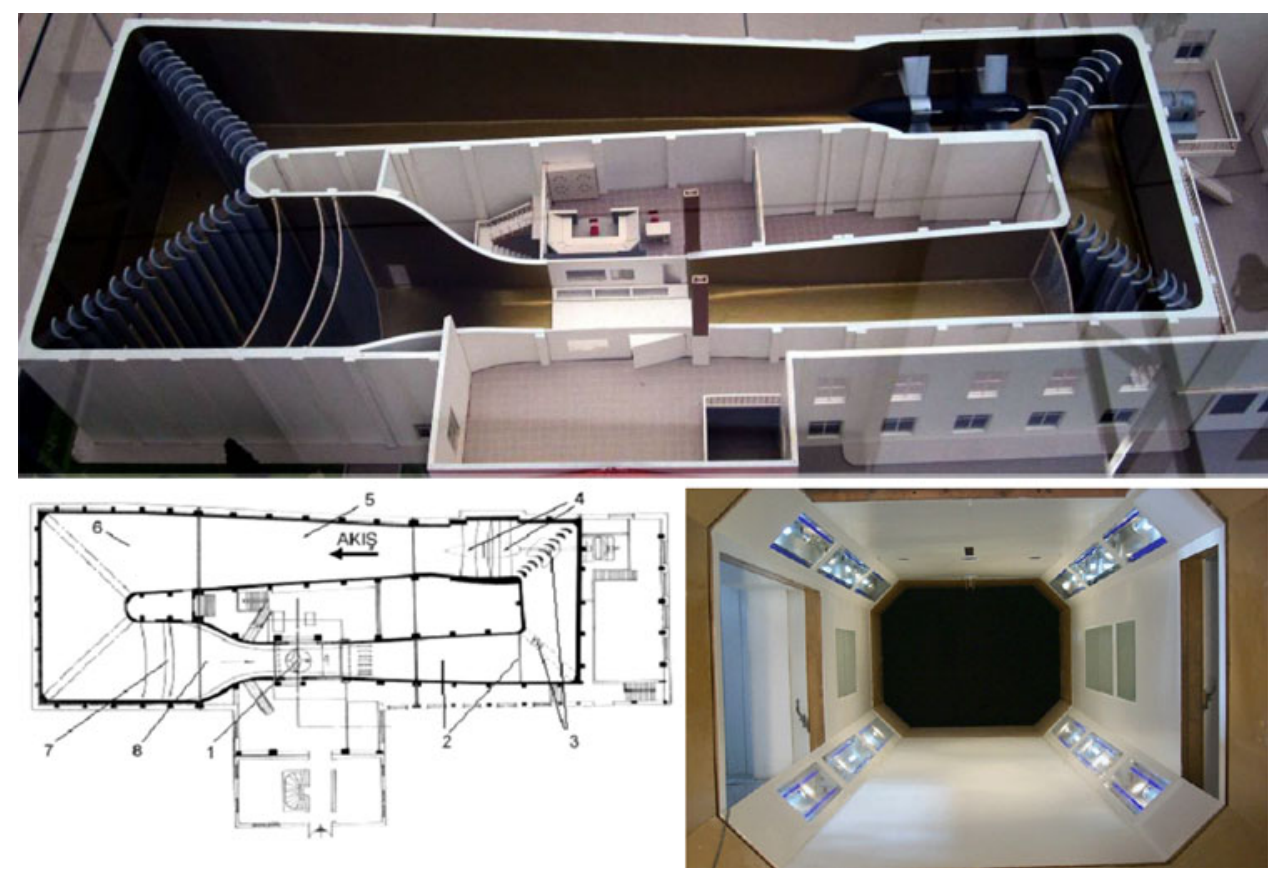


Richardson number : $R i=\left(\Delta T_{0} / T_{0}\right)\left(L_{0} g / U_{0}^{2}\right)$

Rossby number : $R o=U_{0} / L_{0} \Omega_{0}$

Prandtl number : $\operatorname{Pr}=v_{0} \rho_{0} c_{p 0} / k_{0}$

Eckert number : $E c=u_{0}^{2} / c_{p 0}(\Delta \bar{T})_{0}$

In addition, boundary conditions that are needed for "exact" similarity are:

1. Surface roughness and temperature at ground level.

2. Flow structure above the ABL or drainage current.

3. Zero pressure gradients in direction of mean flow.

4. Sufficient upwind fetch to establish equilibrium of the simulated ABL with surface boundary conditions.

5. Height of an inversion layer, if present.

Normal wind tunnel testing under standard atmospheric and gravity conditions typically entails fundamental scale violations for the Reynolds number. Richardson number is needed only for thermal similarity, and since the ABL is essentially independent of the geostrophic wind and the Ekman spiral effect, it can be modeled without matching Rossby number. For wind tunnel simulation in air, the Prandtl number criterion is automatically satisfied, and the Eckert number is only important in compressible flows. This quick review shows that in ordinary wind tunnels, exact matching of the dimensionless parameters of the entire ABL is not possible. Instead, in practice, the geometric scaling of the boundary conditions is tried to be satisfied. For neutral ABL surface layers, the theory introduced by (Cermak 1995) uses only variables defined at the ground surface to describe the entire ABL. These are the surface roughness height, $z_{0}$ and the friction velocity, $u *$.

Definition of the wind profile

In order to achieve ABL simulations in wind tunnels for any type of ground coverage, the upwind exposure category should be based on ground surface roughness that is determined from natural topography, vegetation and constructed facilities. There are several definitions with minor differences for ground surface roughness for modeling the atmospheric boundary layer in wind engineering studies. In this paper, the American Society of Civil Engineers (ASCE) definition is used for ground surface roughness modeling. According ASCE7-05 (American Society of Civil Engineers [ASCE] 2005; Zhou and Kareem 2002), the ground surface roughness categories are divided into three exposure categories: B, C and D.

Exposure B applies to urban and suburban areas, wooded areas or other terrain with numerous closely spaced obstructions having the size of single-family dwellings or larger which prevails in the upwind direction for a distance of at least 2,600 ft $(792 \mathrm{~m})$ or 20 times the height of the building, whichever is greater. Exposure D is for flat, unobstructed areas and water surfaces outside hurricane prone regions which prevails in the upwind direction for a distance greater than $5,000 \mathrm{ft}(1,524 \mathrm{~m})$ or 20 times the building height, whichever is greater. Exposure $\mathrm{C}$ applies for all cases where exposures B or D do not apply.

According to ASCE definition, the $\alpha$ in power-law equation, $U / U_{\infty}=(y / \delta)^{\alpha}$, can be defined as $\alpha=1 / 14.4$ for exposure $\mathrm{B}, \alpha=1 / 16.5 .6 .5$ for exposure $\mathrm{C}$ and $\alpha=1 / 19.9$ for exposure $\mathrm{D}$. The atmospheric boundary layer heights for exposures B, C and D are 365.74, 274.32 and $312.36 \mathrm{~m}$, respectively. These heights are used for modeling $\delta$ (i.e., wind tunnel boundary layer depth) for different scale factors.

Design methodology for spires and roughness elements

Simulation of the ABL in a short wind tunnel requires a significant effort in terms of designing appropriate devices to be added at the entrance of the test section in order to create the desired boundary layer properties upstream of the test subject. This procedure generally includes custom designed spires at the inlet followed by rows of roughness elements placed on the wind tunnel floor. Simiu and Scanlan 1986 proposed the following procedure for the design of spires, which are geometrically defined as presented in Fig. 2a. The base length of the triangular splitter plate in Fig. 2a is $h / 4$, and the lateral spacing between the spires is $h / 2$, where $h$ is the height of a spire. In practice, the width of the tunnel does not need to be an integral multiple of $h / 2$. The design procedure is defined as:

1. Select the desired boundary layer depth, $\delta$.

2. Select the desired shape of the mean velocity profile defined by the power-law exponent.
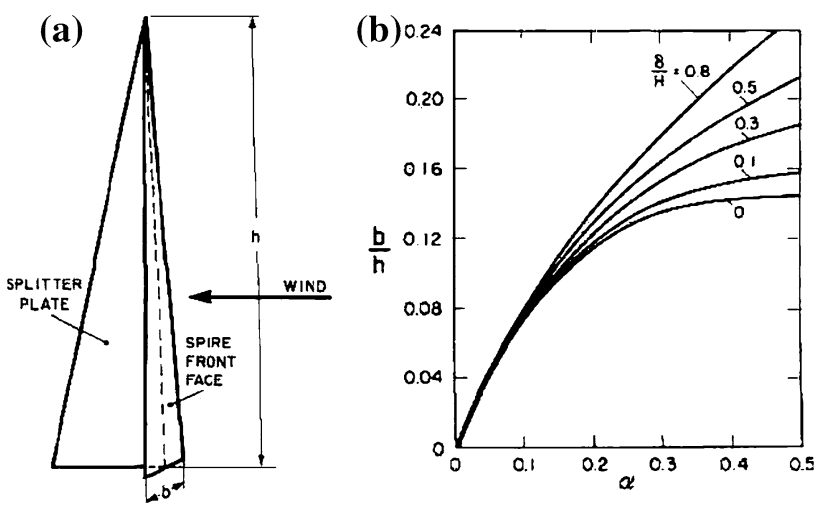

Fig. 2 a A typical spire configuration and b spire base width variation with power-law exponent (Simiu and Scanlan 1986) 
Table 1 The boundary layer characteristics and the geometries of the passive devices for 1/400 scale factor (dimensions in meter)

\begin{tabular}{llllllllllll}
\hline Exposure & $\delta$ & $\alpha$ & $D$ & $X$ & $h$ & $b$ & Splitter & Lateral & $k$ & $\Gamma^{\mathrm{a}}$ & Number of spires \\
\hline B & 0.914 & $1 / 4.0$ & 0.2 & 4.5 & 1.129 & 0.120 & 0.282 & 0.565 & 0.0356 & 5.08 & 4 \\
$\mathrm{C}$ & 0.686 & $1 / 6.5$ & 0.2 & 4.5 & 0.885 & 0.107 & 0.221 & 0.443 & $\sim 0$ & 3.98 & 5 \\
$\mathrm{D}$ & 0.533 & $1 / 9.0$ & 0.2 & 6 & 0.702 & 0.064 & 0.175 & 0.351 & $\sim 0$ & 4.21 & 6 \\
\hline
\end{tabular}

${ }^{a} \Gamma=X \times h$ is the distance downstream of the spires where boundary layer depth is expected to match the selected $\delta$

Fig. 3 Contours of velocity magnitude for exposures $B$, $C$ and $D(1 / 400$ scale $)$ at various cross sections downstream of the test section inlet. Inset figures show the spires and roughness elements configurations for this scale

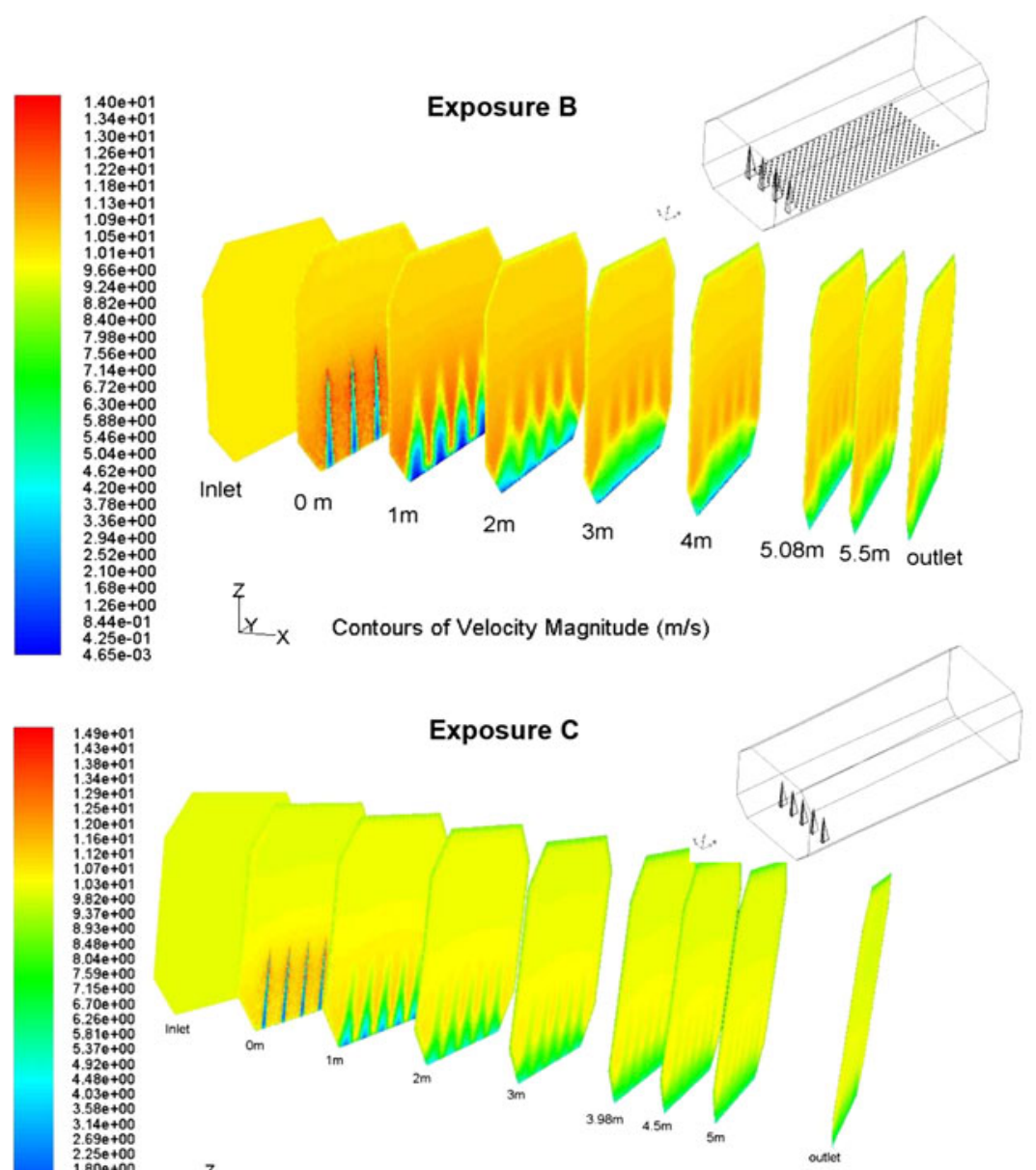

$Z_{x} \quad$ Contours of Velocity Magnitude $(\mathrm{m} / \mathrm{s})$

Exposure D

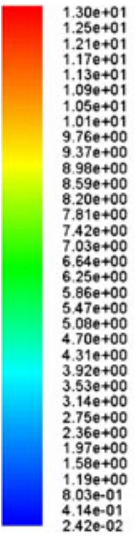

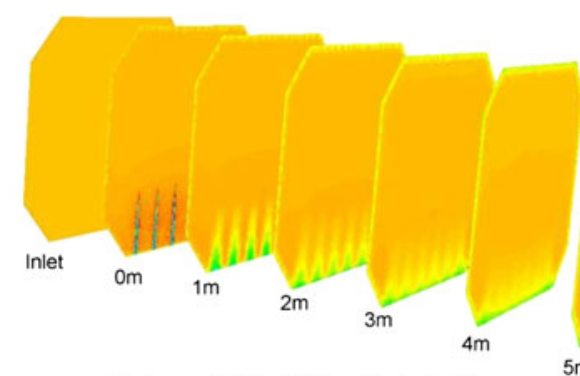

$z$ Contours of Velocity Magnitude $(\mathrm{m} / \mathrm{s})$

${ }^{x} \mathrm{x}$ 
3. Obtain the height $h$ of the spires from the relation

$h=1.39 \delta /(1+\alpha / 2)$

4. Obtain the width of the spire base from Fig. 2b, in which $H$ is the height of the tunnel test section.

Fig. 4 Velocity magnitude contours downstream of the spires on cross sections corresponding to the $\Gamma$ values given in Table 1 . The numerical prediction and power-law velocity profiles along the tunnel height at those cross sections are given on the right
The desired mean wind profile occurs approximately at a distance about $6 h$ downstream from the spires. The wind tunnel floor downwind of the spires should be covered with roughness elements, for example, cubes with height $k$ such that:
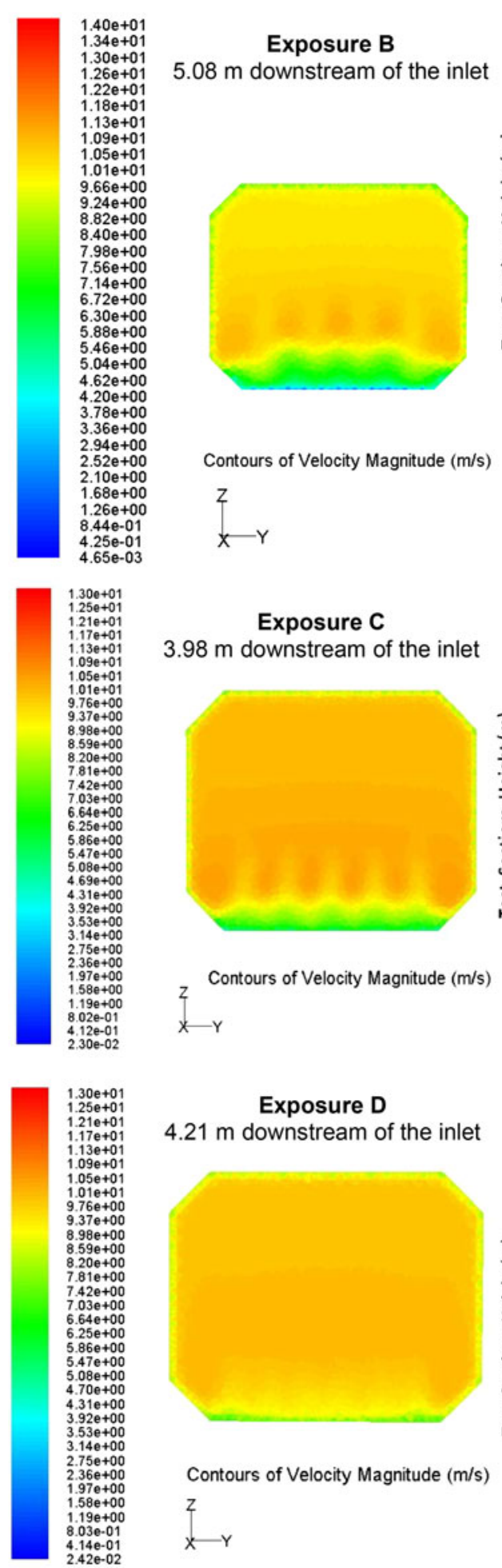

Exposure D

$4.21 \mathrm{~m}$ downstream of the inlet

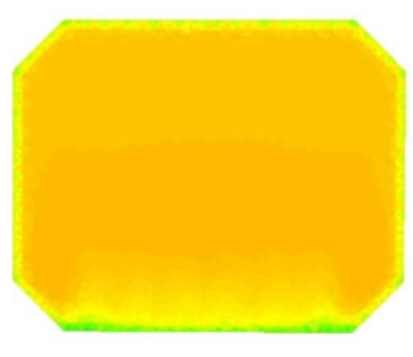

Contours of Velocity Magnitude $(\mathrm{m} / \mathrm{s})$ z $X-Y$
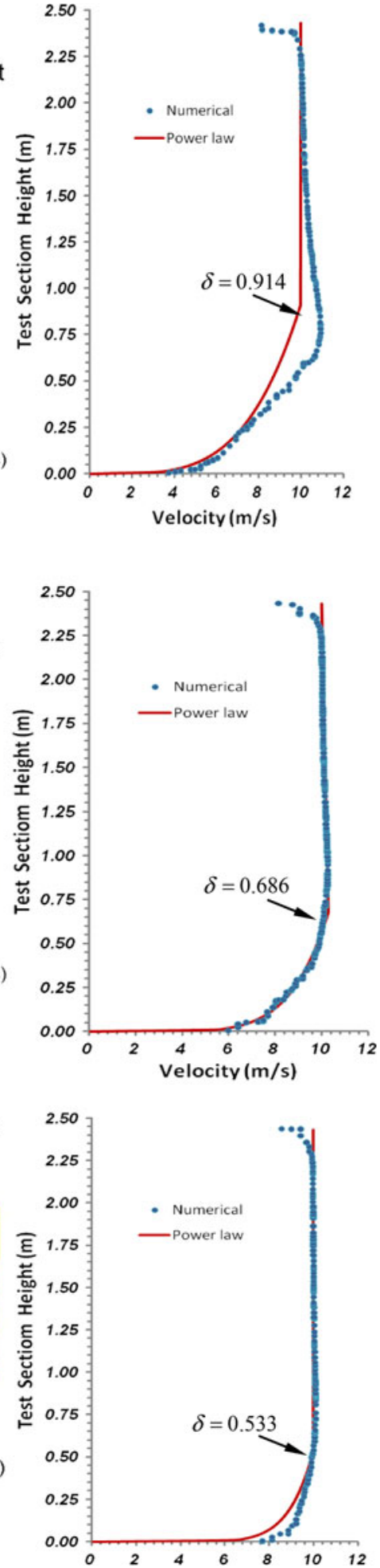
Table 2 Geometrical parameters for the re-designed spires and roughness elements (dimensions in meter)

\begin{tabular}{lllllllllllll}
\hline Exposure & Scale factor & Model height & $\delta$ & $\alpha$ & $D$ & $X^{\mathrm{b}}$ & $h$ & $b$ & Splitter & Lateral & $k$ & $\Gamma^{\mathrm{c}}$ \\
\hline B & $1 / 500$ & 0.4 & 0.731 & $1 / 4.0$ & 0.2 & 4.5 & 0.904 & 0.158 & 0.226 & 0.452 & 0.033 & 4.07 \\
$\mathrm{C}$ & $1 / 400$ & 0.5 & 0.686 & $1 / 6.5$ & 0.2 & 4.5 & 0.885 & 0.107 & 0.221 & 0.443 & $\sim 0$ & 3.98 \\
$\mathrm{D}$ & $1 / 285$ & 0.7 & 0.747 & $1 / 9.0$ & 0.2 & 4.5 & 0.983 & 0.091 & 0.246 & 0.492 & $\sim 0$ & 4.43 \\
\hline
\end{tabular}

${ }^{a}$ Model height presented here is based on simulation of $200 \mathrm{~m}$ building height in wind tunnel and could be any other height based on the other building heights in various conditions

${ }^{\mathrm{b}} X$ is factor of $h$ for creation boundary layer instead of $6 h$ downstream of spires

${ }^{\mathrm{c}} \Gamma=X \times h$ is the distance downstream from the spires which boundary layer expected to be match by selected $\delta$

Fig. 5 Velocity magnitude contours for the re-designed inlet configurations downstream of the spires on cross sections corresponding to the $\Gamma$ values given in Table 2. The numerical prediction and power-law velocity profiles along the tunnel height at those cross sections are given on the right
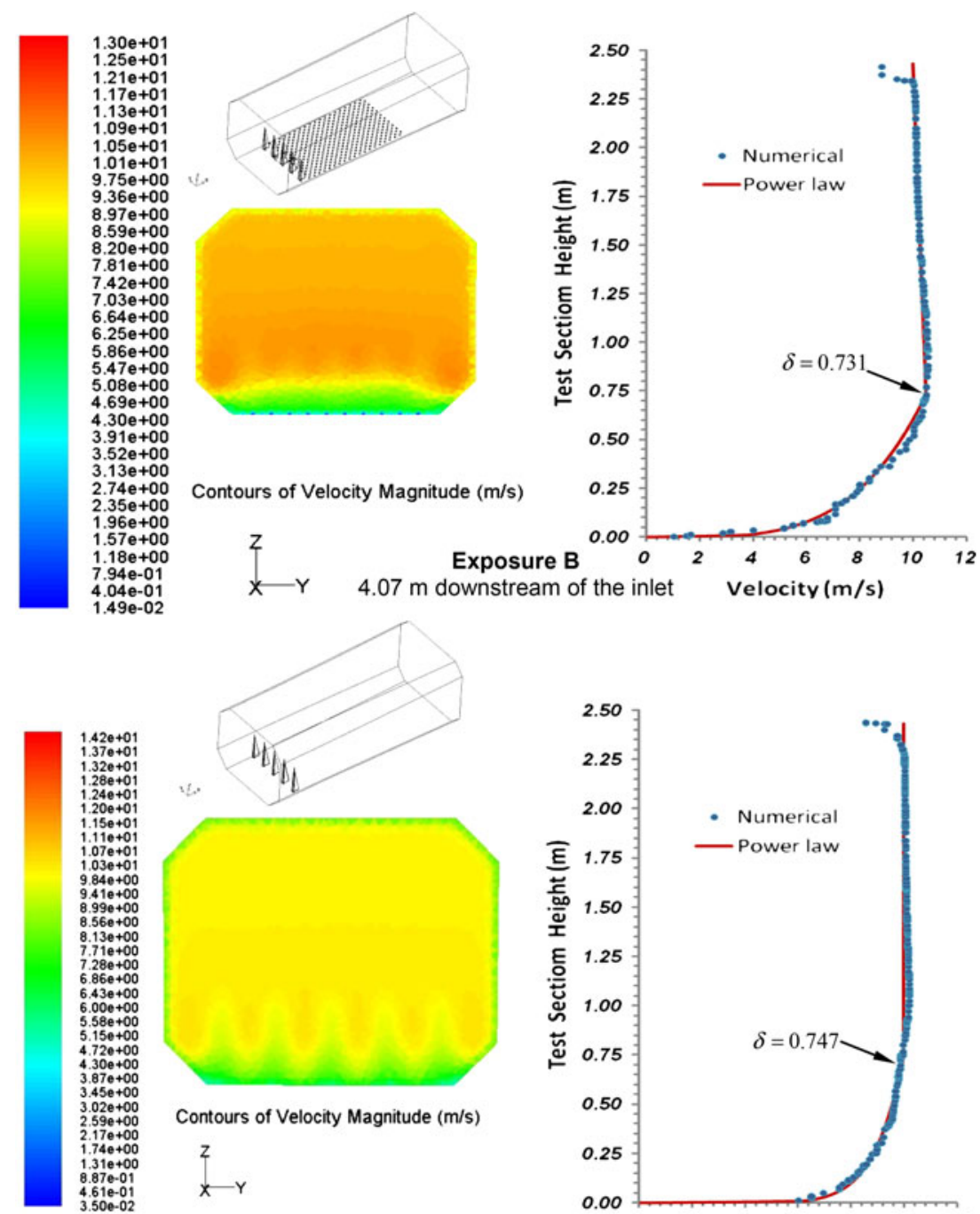

Exposure D

$4.43 \mathrm{~m}$ downstream of the inlet

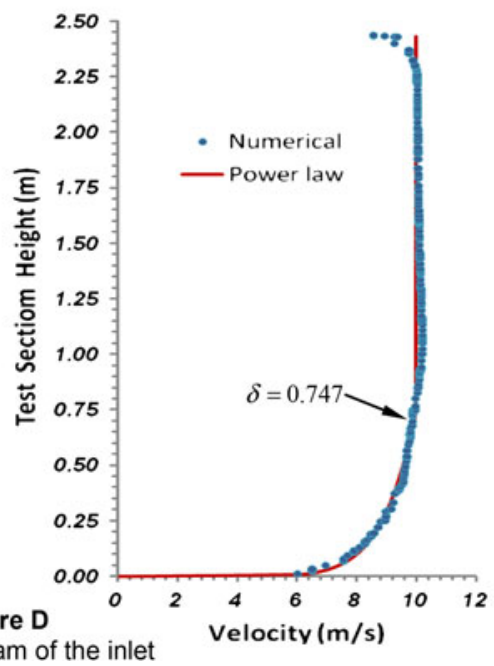

Equation 8 is valid in the range of $30<\alpha D^{2} / k^{3}<2,000$.

In terms of achieving similarity in turbulence levels in the laboratory and in the atmospheric flow, regardless of the type of passive devices being used, simulations in short wind tunnels generally do not achieve similitude (Simiu and Scanlan 1986).
$C_{f}=0.136[\alpha /(1+\alpha)]^{2}$ 
Fig. 6 Manufactured spires and roughness element configurations for three different exposures
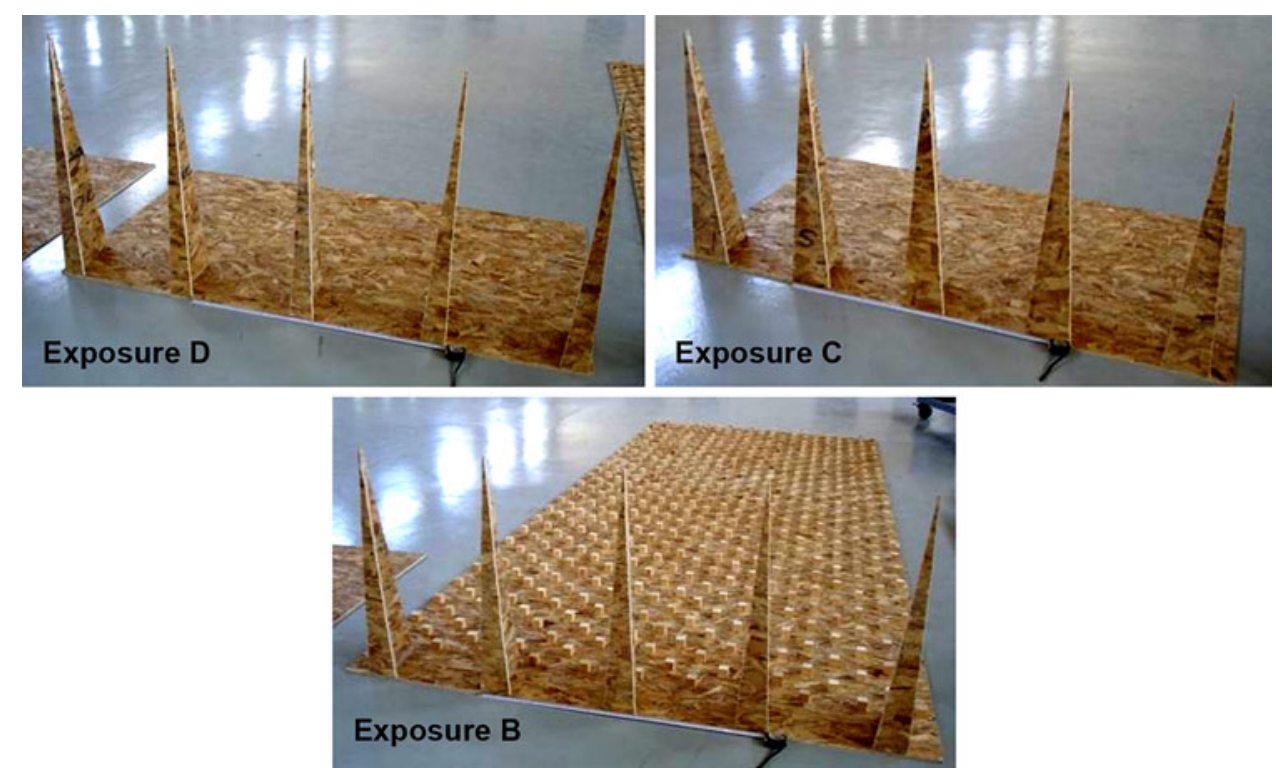

\section{Results and discussion}

The spires and roughness elements are first designed to obtain required $\mathrm{ABL}$ similarity within the test section of the Ankara Wind Tunnel using the design methodology described above. Subsequently, a computational analysis of the designed inlet configurations is performed using CFD to have a preliminary understanding of how well the inlet configurations could simulate the desired boundary layer conditions within the test section. The design goal is to obtain a boundary layer characteristic for the model testing of a $200 \mathrm{~m}$ high building in exposures B, C and D.

As an initial attempt, we selected a model building height of $0.5 \mathrm{~m}$ (i.e., scale factor of 1/400) and a wind tunnel speed of $10 \mathrm{~m} / \mathrm{s}$ for all three exposures B, C and D. By using methodologies given in the previous section, the geometries of the spires and cubical roughness elements are calculated as listed in Table 1.

The computational analysis of the AWT test section is performed with the spires and roughness elements for all three exposure categories using the commercial CFD software Fluent. The number of computational cells depends on the exposure category and is generally between 1.3 and 1.7 million tetrahedral cells. Results of the computational simulations are obtained by solving RANS equations using $\kappa-\varepsilon$ turbulence model, with standard pressure, second order momentum, turbulent kinetic energy and turbulent dissipation rate computations.

Figures 3 and 4 show the results of the computational simulations for the $1 / 400$ scale ABL. The effects of the spires and the roughness elements are clearly visible in

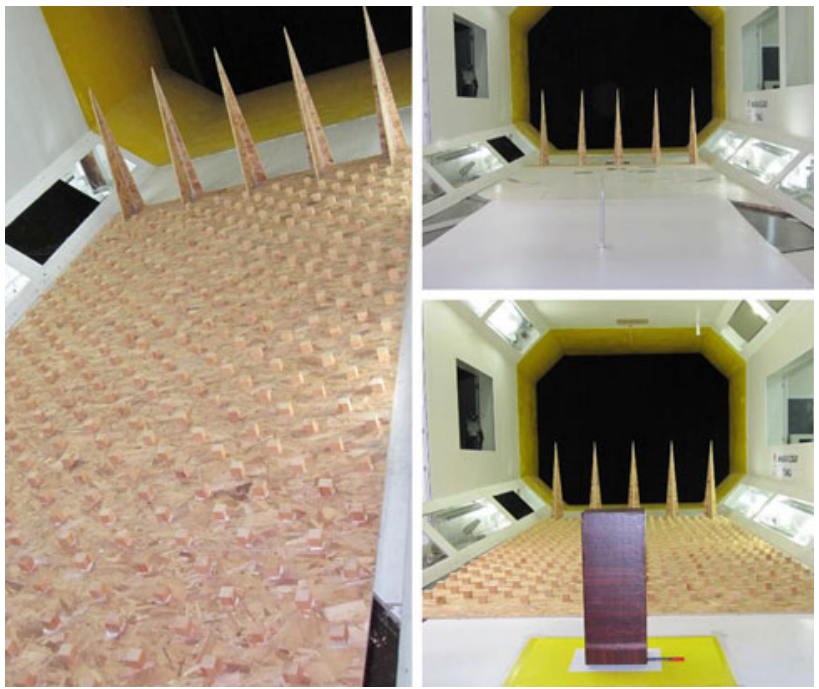

Fig. 7 Ankara Wind Tunnel test section with passive devices installed for experimental test

Fig. 3. For exposure B, the individual wakes of the spires are identifiable up to about $2 \mathrm{~m}$ downstream of the test section entrance. These wakes as well as the disturbances created by the cubical roughness elements start to mix out and create a thick boundary layer near the wall as one moves downstream. For the other two exposures, because of the missing roughness elements, individual spire wakes persist much longer.

Figure 4 presents the velocity magnitude contours downstream of the spires on cross sections corresponding to the $\Gamma$ values given in Table 1 . The numerically predicted 
Fig. 8 Experimental results versus $C F D$ and power low data for exposure $B, C$ and $D$
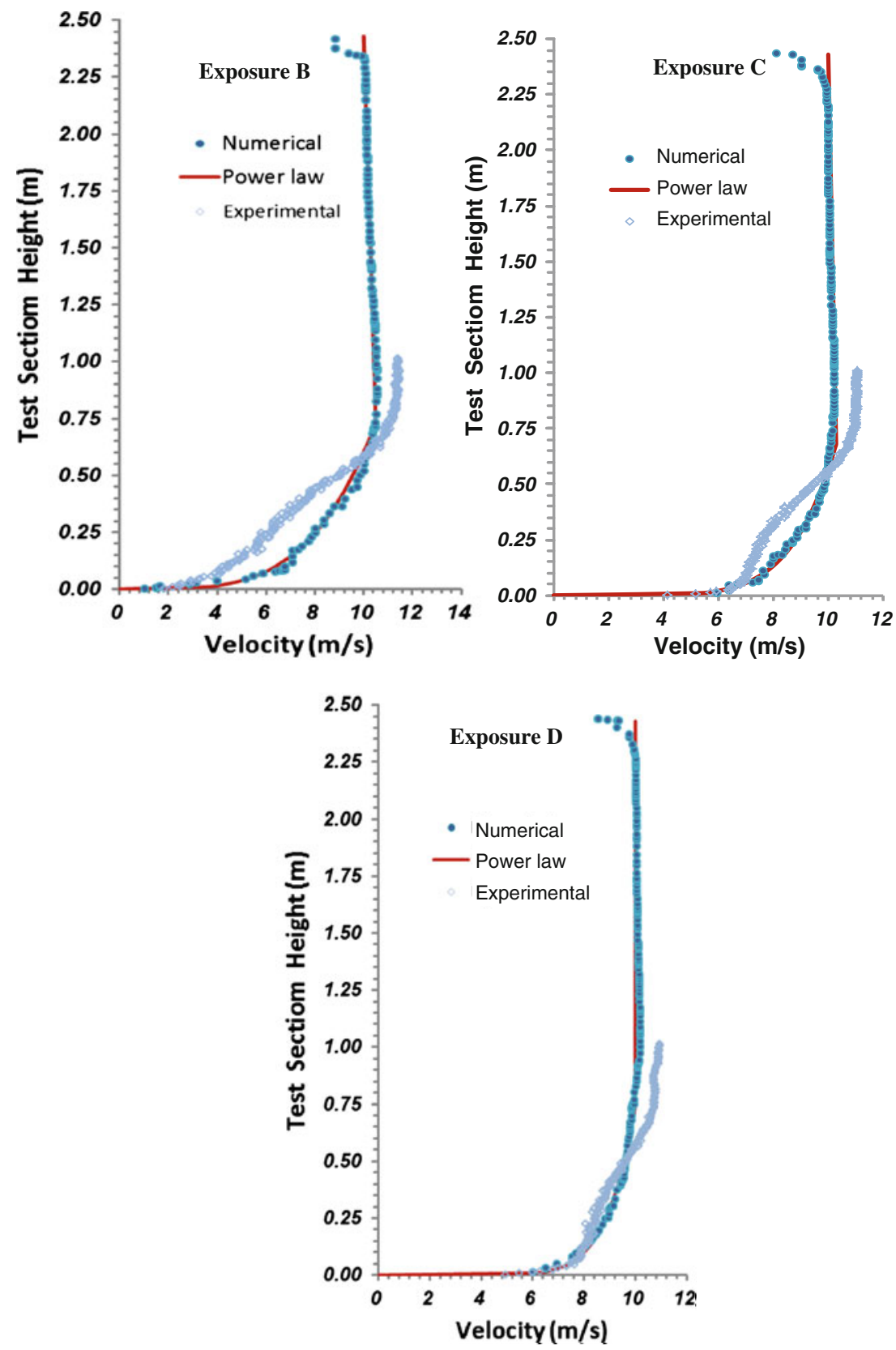

and power-law velocity profiles along the tunnel height at those cross sections are given on the right column. The CFD results show that although the required boundary layer profile is very well obtained for exposure $\mathrm{C}$, for exposures B and D the desired power-law boundary layer profiles cannot be reproduced exactly by the designed spire and roughness configurations. Although the reliability of the CFD results can also be questionable, current results still indicate that the inlet configuration design for exposures B and D may not be appropriate for the experiments.
In order to produce more appropriate inlet configurations for exposures $\mathrm{B}$ and $\mathrm{D}$ and as a second iteration in the design process, the spires and roughness elements are re-designed with different scale factors. In this second iteration, the scale factors for exposures $\mathrm{B}$ and $\mathrm{D}$ are chosen such that the desired boundary layer heights are about $30 \%$ of the tunnel height, similar to the case for exposure $\mathrm{C}$ in the first design iteration. This resulted in scale factors of $1 / 500$ and $1 / 285$ for exposures B and D, respectively. The geometrical parameters for the re- 
designed spires and roughness elements are presented in Table 2.

Figure 5 shows the velocity magnitude contours for the re-designed inlet configurations downstream of the spires on cross sections corresponding to the $\Gamma$ values given in Table 2 . The predicted and the desired powerlaw velocity profiles along the tunnel height show much better agreement compared to the first design iteration. As a result, it was decided that the geometrical inlet configurations given in Table 2 will be used in the building model experiments in the AWT. For this purpose, all three inlet configurations corresponding to the different exposure categories are produced as shown in Fig. 6.

Figure 7 shows Ankara Wind Tunnel test section with passive devices installed for experimental test. The test done in the AWT by using hotwire anemometry and specific traverse gear. The results are presented in Fig. 8 and show acceptable agreement with CFD and power-law results.

The created boundary layers in wind tunnel shown in Fig. 8 confirm acceptable wind profile for $0.731 \mathrm{~m}$ boundary layer thickness at $4.07 \mathrm{~m}$ downstream of $0.904 \mathrm{~m}$ spire height to modeling $0.4 \mathrm{~m}$ model height for exposure B, also $0.686 \mathrm{~m}$ boundary layer thickness at $3.98 \mathrm{~m}$ downstream of $0.885 \mathrm{~m}$ spire height to modeling $0.5 \mathrm{~m}$ model height for exposure $\mathrm{C}$ and finally $0.747 \mathrm{~m}$ boundary layer thickness at $4.43 \mathrm{~m}$ downstream of $0.983 \mathrm{~m}$ spire height to modeling $0.7 \mathrm{~m}$ model height for exposure D.

These wind profile categories would be used in future high-raised building studies in Ankara Wind Tunnel's wind engineering modeling to find more accurate building behaviors and wind effects on structures such as bridges and towers in Turkey.

\section{Conclusion}

This paper presents the design, computational analysis and experimental test of different inlet configurations that have been applied to the test section of Ankara Wind Tunnel in order to simulate the atmospheric boundary layer characteristics within the test section for three different exposure categories. This design used in the wind tunnel tests of high-rise buildings to generate appropriate boundary layer properties within the test section. The design consists of spires and rows of cubical surface roughness elements at the inlet. The preliminary computational analysis shows that the current design may provide the desired boundary layer thickness at about 4 up to $4.5 \mathrm{~m}$ downstream of the test section inlet, which leaves enough room for the high-rise building model. This study helps us obtaining a preliminary understanding of the boundary layer development, and it will also help us to reduce the tunnel operation time and cost during the actual experimentation phase.

Acknowledgments Authors would like to express their very great appreciation to the staff of the TÜBİTAK SAGE, Ankara Wind Tunnel, and the Aerospace and Civil Engineering Departments at Middle East Technical University for their supports during this study. Also special thanks are extended to Mrs. Bengi KAYIŞOĞLU for her corporation in this study.

\section{References}

Abbaspour M, Shojaee MN (2009) Innovative approach to design a new national low speed wind tunnel. Int J Environ Sci Tech $6(1): 23-34$

Abdullah LC, Wong LI, Saari M, Salmiaton A, Abdul Rashid MS (2007) The Particulate matter dispersion and Haze occurrence potential studies at a Local Palm oil Mill in Malaysia. Int J Environ Sci Tech 4(2):271-278

American Society of Civil Engineers (ASCE) (2005) Minimum design loads for buildings and other structures. ASCE7-05

Bienkiewicz B (1996) New tools in wind engineering. J Wind Eng Ind Aerodyn 65(1-3):279-300

Cermak EJ (1982) Physical modeling of the atmospheric boundary layer (ABL) in long boundary layer wind tunnel (BLWT). Fluid Dynamics and Diffusion Lab, College of Civil Eng Colorado state University, Fort Collins

Cermak EJ (1995) Progress in physical modeling for wind engineering. J Wind Eng 55:439-455

Cermak JE (2003) Wind tunnel developments and trends in applications to civil engineering. J Wind Eng Ind Aerodyn 91:355-370

Cermak EJ, Cochran LS, Leffler RD (1995) Wind tunnel modeling of the atmospheric surface layer. J Wind Eng 54(55):505-513

Cook NJ (1973) On simulating the lower third of the urban adiabatic boundary layer in a wind tunnel. Atmos Environ 7:691-705

Counihan J (1969) An Improved method of simulating an atmospheric boundary layer in a wind tunnel. Atmos Environ 3:197-214

Counihan J (1973) Simulation of an adiabatic urban boundary layer in a wind tunnel. Atmos Environ 7:673-689

Freddy Kho WL, Sentian J, Radojevic M, Tan CL, Law PL (2007) Computer simulated versus observed $\mathrm{NO}_{2}$ and $\mathrm{SO}_{2}$ emitted from elevated point source complex. Int $\mathbf{J}$ Environ Sci Tech 4(2):215-222

Garg RK, Lou JX, Kasperski M (1997) Some features of modeling spectral characteristics of flow in boundary layer wind tunnels. J Wind Eng 72:1-12

Irwin HP (1981) The design of spires for wind simulation. J Wind Eng Ind Aerodyn 7:361-366

Nagheeby M, Kolahdoozan M (2010) Numerical modeling of twophase fluid flow and oil slick transport in estuarine water. Int $\mathbf{J}$ Environ Sci Tech 7(4):771-784

Ohya Y (2001) Wind- tunnel study of atmospheric stable boundary layer over a rough surface. Bound Layer Meteorol 98:57-82 
Peishi Q, Zhiguo S, Yunzhi L (2011) Mathematical simulation on the oil slick spreading and dispersion in non uniform flow fields. Int J Environ Sci Tech 8(2):339-350

SAGE (1998). http://www.sage.tubitak.gov.tr/aerodinamik/art.asp
Simiu E, Scanlan R (1986) Wind effects on structures, 2nd edn. Wiley, New York

Zhou Y, Kareem A (2002) Definition of wind profiles in ASCE 7. J Struct Eng 128:1082-1086 